\title{
Review
}

\section{Insulin Peptides as Mediators of the Impact of Life Style in Alzheimer's disease}

\author{
A.M. Fernandez, A. Santi and I. Torres Aleman* \\ Cajal Institute and Ciberned, Madrid, Spain
}

Accepted: 11 May 2018

Published: 6 June 2018

\begin{abstract}
The search for the cause of Alzheimer's disease (AD), that affects millions of people worldwide, is currently one of the most important scientific endeavors from a clinical perspective. There are so many mechanisms proposed, and so disparate changes observed, that it is becoming a challenging task to provide a comprehensive view of possible pathogenic processes in AD. Tauopathy (intracellular neurofibrillary tangles) and amyloidosis (extracellular amyloid plaques) are the anatomical hallmarks of the disease, and the formation of these proteinaceous aggregates in specific brain areas is widely held as the ultimate pathogenic mechanism. However, the triggers of this dysproteostasis process remain unknown. Further, neurofibrillary tangles and plaques may only constitute the last stages of a process of still uncertain origin. Thus, without an established knowledge of its etiology, and no cure in the horizon, prevention -or merely delaying its development, has become a last-resort goal in $\mathrm{AD}$ research. As with other success stories in preventive medicine, epidemiological studies have provided basic knowledge of risk factors in AD that may contribute to understand its etiology. Disregarding old age, gender, and ApoE4 genotype as non preventable risk factors, there are diverse life-style traits -many of them closely related to cardiovascular health, that have been associated to AD risk. Most prominent among them are diet, physical and mental activity, exposure to stress, and sleep/wake patterns. We argue that all these life-style factors engage insulinergic pathways that affect brain function, providing a potentially unifying thread for life-style and AD risk. Although further studies are needed to firmly establish a link between faulty insulinergic function and $\mathrm{AD}$, we herein summarize the evidence that this link should be thoroughly considered.
\end{abstract}

Keywords: Insulin peptides, life-style, risk of Alzheimer disease, diet, physical and mental activity, stress, sleep/wake cycle

\section{INTRODUCTION}

The first description of an AD patient was made over a hundred years ago [1]. In turn, the most accepted proposal of the origin of this disease -the "amyloid cascade" hypothesis [2], was made decades ago. However, this age-associated mental disorder is the only one among top causes of death that remains intractable. An important barrier to ameliorate the current worrying situation is chronic underfunding

${ }^{*}$ Correspondence to: I. Torres Aleman, Cajal Institute and Ciberned, Madrid, Spain. E-mail: torres@cajal.csic.es. of $\mathrm{AD}$ research, as compared to other high-impact diseases such as cancer [3]. Probably, a profound re-thinking of what we actually know about this uniquely human disease is also required to lead us to new scenarios [4]. All AD researchers would agree that we need new animal models because available ones -that have been extraordinarily useful, do not mimic very important traits of the disease [5]. Even more dismaying, they have not helped to translate pre-clinical findings into clinically useful therapies. Brain pathology in $\mathrm{AD}$ is heterogeneous and somewhat blurs with closely related pathologies such as vascular dementia [6]. The latter aspect has not been 
faithfully captured by experimental modeling, and confronts us with the increasingly more recognized possibility that $\mathrm{AD}$ is not a single nosological entity.

From epidemiological studies we know that many life-style factors pose varying degrees of AD risk [7, 8]. Together with age -the main risk factor, ApoE genotype and sex -the main genetic risk factors (although many other genes are also associated to $\mathrm{AD}$ risk), behaviorally regulated factors such as diet, physical and mental activity (including social engagement and educational achievement), exposure to stress, and sleep patterns, are so far considered major modulators of AD pathology [9]. Accordingly, this knowledge has been used to implement intervention schemes that are now ongoing on a global scale, as reflected by the abundant literature on the topic [10-13]. An additional utility of this epidemiological information is that it may lead to a better understanding of the causes of AD. Based on this variety of risk factors two general questions arise. Are there many risk factors in AD because there are many potential causes for developing it? Alternatively, are all these risk factors affecting a common pathogenic pathway? Acknowledging that we still do not have enough data to favor any of these two general options and a combination thereof [4], we propose to explore the latter possibility in relation to the function of insulinlike peptides (ILPs), as there is enough evidence to entertain this notion. Vertebrate ILPs comprise three families of related hormones: insulin and its related insulin-like growth factor I and II (IGF-I and IGF-II), relaxins, and insulin-like peptides. For the purpose of this review we refer to insulin and IGFs as ILPs, as this family is the best studied in the central nervous system.

Please note that our proposal is entirely operational, as we consider that AD most likely is triggered by more than a single pathogenic event. Specifically, we propose that faulty ILP function in the brain is a main pathogenic pathway in $\mathrm{AD}$ because, as pointed out before [14], all major disturbances associated to the pathology can be explained by altered ILP activity (Fig. 1). For example, ILPs are major regulators of synaptic activity and number. Thus, insulin, IGF-I and IGF-II promote synapse formation and synaptic plasticity [15-17]. Insulin and IGF-I are also positive modulators of proteostasis [18-20], including amyloid $\beta(\mathrm{A} \beta)$ processing [21-24]. By inhibiting GSK-3 $\beta$, a major Tau kinase, both insulin and IGF-I modulates Tau phosphorylation [25, 26]. Both ILPs are also important to preserve mitochondrial function $[27,28]$, combat oxidative stress $[29,30]$ and inflammation [31, 32], and protect the brain vasculature [33]. Further, all three ILPs modulate mood in a positive fashion [34-36]. Importantly, a close connection between diabetes and AD has been suggested $[37,38]$, and numerous processes possibly connecting both diseases have been proposed [39-41]. Of note, diabetes not only alters insulin activity, but also reduces IGF-I levels [42]. Indeed, merely reducing insulin-like growth factor I (IGF-I) input to the brain elicited tauopathy, amyloidosis, cognitive deterioration and synaptic disturbances in rodents [43]. In addition, genome-wide analysis in pilot studies hint to a possible association of ILP-related genes with AD risk [44-46]. Finally, while there is still no evidence of a connection between ILPs and sex bias in AD incidence, many actions of ILPs in brain are sexually dimorphic [47-49]. Hence, this ILPs trait may also underlie varied AD incidence between both sexes [50]. In this regard, it is interesting to note that IGFII is an X-linked imprinted gene and that epigenetic changes including alterations in genomic imprinting may affect the risk of $\mathrm{AD}$ [51].

However, it is important to point out that disturbed ILP function, as for example in diabetes, does not always originate cognitive disturbances. Maybe, altered ILP activity is necessary, but not sufficient to trigger AD pathology. Alternatively, diabetic patients with preserved brain function may have developed unknown protective mechanisms, similarly to what occurs with old individuals showing intact cognitive function despite displaying conspicuous AD-like neuropathology [52]. Additionally, it is important to remember that many studies in animal models, and even in humans, point to a deleterious role of ILPs, specifically insulin and IGF-I, in aging [53] and in age-related diseases, including AD [54]. The so called "insulin paradox" $[55,56]$ refers to the observation that reduction of insulin/IGF-I signaling promotes longevity in invertebrate species and in mammals [57], and protects against AD in mouse models $[58,59]$. Conversely, IGF-I, IGF-II, and insulin display varied neuroprotective actions, including potentiation of learning and memory, and protection against $\mathrm{AD}[60]$.

ILPs constitute a well preserved family of hormones already present in primitive invertebrates. In the latter, ILPs share a common single receptor, whereas vertebrate insulin and IGFs share three receptors, with differing affinities. Insulin binds with highest affinity to its receptor-showing two isoforms, IR-A and IR-B [61], and with lower affinity to the IGF-I receptor (IGF-IR), and the hybrid insulin/IGF-I 


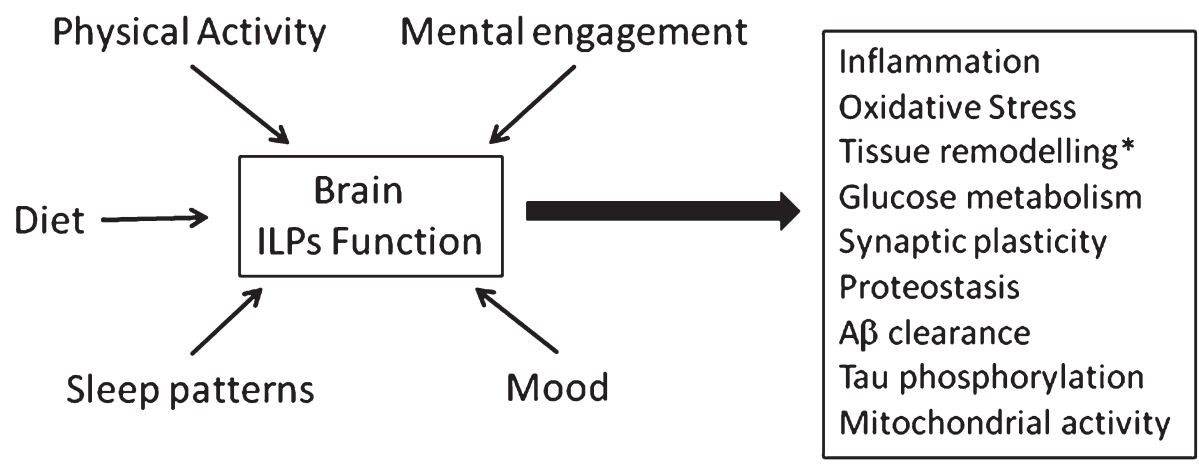

Fig. 1. Altered ILP function mediates the impact of life-style factors on pathological changes associated to Alzheimer's disease. Diet, mental and physical activity, sleep quality and mood can modulate ILP function that in turn intervene in many processes known to be altered in $\mathrm{AD}$. Main ones include homeosteatic inflammation, protection against reactive oxygen species, tissue remodelling (including formation of new vessels, neurons and glia), glucose handling by brain cells, synaptic plasticity -that in turn impacts on mood, cognition, and sleep architecture, $\mathrm{A} \beta$ clearance, tau phosphorylation, proteostasis (autophagy, proteosome activity) and mitochondrial function. *New neuronal formation is an important aspect of ILPs function in the adult brain. However, recent controversial evidence in favor [192] or against [193] the presence of neurogenesis in the adult human brain puts somewhat in hold the significance of this ILP trait in human physiology.

receptor (IR/IGF-IR). IGF-I binds to highest affinity to its receptor and the hybrid IR/IGF-IR [62], and with lower affinity to IR and IGF-IIR. IGFII binds with highest affinity to IGF-IIR and IR-A [63], and with lower affinity to IGF-IR and IR-B. An important feature of brain ILPs is their varied sources. Insulin is mostly produced in the pancreas, but low levels of expression are found in the adult brain [64]. This means that circulating insulin gets into the brain by crossing the cells of the bloodbrain-barriers through a transcytosis process [65]. Despite its profound functional impact in brain physiology, the precise mechanism allowing serum insulin to transverse the BBB is still not well characterized. IGF-I is also locally produced by adult brain cells [66, 67], but a major proportion of brain IGF-I comes also from the periphery. Indeed, the adult brain expresses very low amounts of IGF-I as compared to the developing brain, but the amount of brain IGF-I is relatively constant throughout ontogeny (a decrease is seen at old age). In the case of serum IGF-I, the mechanisms involved in its passage into the brain are better characterized [68, 69]. Lastly, IGF-II is produced at high levels by the choroid plexus and meninges [70], so it is likely that brain IGF-II derives from these tissues. Greater detail of the different sources and mechanisms of transcytosis of brain ILPs is provided in Fernandez et al., 2012 [60].

\section{Diet}

A balanced diet is necessary for a healthy cardiometabolic status. Evidence that a healthy diet may also contribute to prevent or delay $\mathrm{AD}$ [71] is generally interpreted from the cardio-metabolic point of view. That is, preserved tissue perfusion -as a result of a healthy vasculature [72], and intact insulin sensitivity $[72,73]$ will explain the protective actions of a balanced diet on brain function. However, there is evidence that diet also affects brain function through a direct modulation of the actions of ILPs in the brain. Specifically, diet components such as lipids modulate the entrance of circulating IGF-I and insulin through the blood-brain-barrier $[74,75]$. Furthermore, insulin resistance associated to imbalanced diets also reduces brain insulin sensitivity through mechanisms as yet unknown [76, 77], but that probably encompass reduced entrance of insulin into the brain. In turn, the known connection between metabolic status -which is highly diet-dependent, neuroinflammation [78], and oxidative stress [79], may be explained in part also by loss of the anti-inflammatory and anti-oxidant actions of insulin/IGF-I [80-82]. Thus, neuroinflammation and oxidative stress reduces insulin/IGF-I signaling in target cells $[83,84]$. Therefore, a vicious cycle develops where deleterious actions of inflammation and oxidative stress on insulin/IGF-I sensitivity reduce their anti-inflammatory and anti-oxidant actions in the brain.

Formerly, the majority of reports identifying a proper diet as a protective factor in AD were crosssectional studies generally using a relatively small sample size [85-89]. More recently, retrospective longitudinal studies with large populations have been implemented. Based on them, the favored idea is 
that low-fat, low-sugar diets are protective [90, 91], although cholesterol intake has been shown not to influence AD risk [92]. The prototypical example of a beneficial diet is the so-called Mediterranean diet [87], but more work is needed to firmly establish its protective role [93]. A corollary of these observations is that obesity is a risk factor for AD. Indeed, many studies confirm an association of obesity with cognitive alterations [94], and increased AD risk [95, 96] These epidemiological studies comprise large populations and therefore their conclusions are more robust.

Many nutritional studies have focused on particular macro- and micro-nutrients to determine their influence in AD pathology. Among those analyzing large cohorts, high glycemic [97], or high-fat content [98] diets (but see [91] have proven deleterious. Conversely, diets rich in fish [99, 100] or B vitamins $[101,102]$ have been shown to be protective. For micro-nutrients such as vitamin E [103], omega-3 fatty acids [104], or folic acid [105], there is still insufficient evidence to determine their influence, if any, on $\mathrm{AD}$ pathology. However, $\mathrm{AD}$ patients show specific micronutrient deficiencies [106], and a micronutrient-based nutriceutical has shown promising protective effects in a small group of $\mathrm{AD}$ patients [85].

An important observation further reinforcing a link between metabolic status and $\mathrm{AD}$ is that $\mathrm{AD}$ patients often present weight loss [107-109]. Emaciation in $\mathrm{AD}$ patients has been ascribed to multiple factors, including an altered hypothalamus-pituitary-adrenal axis [110], which is closely related to IGF-I function in the brain (Santi, submitted). Further, since insulin is a key adiposity signal [111], it might be that faulty insulin function in the AD hypothalamus contributes to abnormal feeding behavior in these patients.

\section{Physical activity}

Together with a balanced diet, proper amount of physical activity is probably the most modifiable lifestyle factor for populations at risk worldwide, particularly in developed countries. However, it is as difficult to implement in the general population, as it is to promote balanced diets [112]. This explains the current intense search for drug mimetics of exercise [113]. Increasing physical activity to reduce risk of $A D$ is one of the few behaviors widely acknowledged to be effective [114], including organizations such as The Alzheimer's Association [9]. Again, reported beneficial effects of physical activity in $\mathrm{AD}$ prevention are usually ascribed to its cardio-protective actions, with gender posing different effects $[115,116]$.

A steadily increasing number of reports document protective actions of physical activity on $\mathrm{AD}$ risk. Currently, the focus is to delineate the minimal amount of activity that is protective [117, 118], and whether it will also be therapeutic [119, 120]. An ancillary effect of these increasingly generalized analyses is the wide use of exercise regimes for treatment of AD patients [121]. Thus, exercise is not only preventive but may also be beneficial for treatment, once $\mathrm{AD}$ pathology is established.

Because exercise improves brain insulin sensitivity [122], and increases brain uptake of circulating IGF-I [68], a direct connection of neuroprotection by exercise with enhanced brain activity of ILPs is straightforward. Intensity, type, length, and frequency of exercise, all may affect ILP function in target tissues [123-125], including the brain. Direct proof of IGF-I-dependent neuroprotection by exercise in animal models [126, 127] has widened to include many other trophic signals [128], which allow us to consider that the main neuroprotective action of exercise is to maintain appropriate levels of trophic support, in many cases arising from the periphery.

Why is exercise required? As pointed out many times, the problem is the abnormally low level of physical activity that is the norm in the modern world $[129,130]$. Thus, sedentarism impedes proper trophic support to the brain, essential for homeostatic maintenance of brain function.

\section{Stress}

A substantial proportion of patients with mild cognitive impairment (MCI) present depressive symptoms. In addition, AD patients frequently have depression as co-morbidity $[131,132]$. While the proportion of affected patients differ depending on the study, it is clear that psychiatric co-morbidities are of great impact in the disease [133, 134]. Depression often antecedes the appearance of overt cognitive deterioration [135, 136], and it is generally assumed that exposure to stress is a main triggering mechanism of depression [137]. Therefore, altered mood regulation can be considered an integral part of the disease. Indeed, AD patients are usually prescribed with psychoactive drugs [133], a component of current medical treatment that requires further insight due to its multiple unwanted effects [110].

Retrospective epidemiological studies indicate that exposure to stress is a risk factor for $\mathrm{AD}$ 
[135], but whether depression is related to the origin of the disease, or it is a consequence of it, is still unknown. Several reports document a link between $\mathrm{AD}$ and brain changes elicited by stress. These include tau missorting [138], altered pro-inflammatory cytokines profile [139], disturbed hypothalamic-pituitary-adrenal (HPA) axis [140], or impaired mitochondrial function [141]. An additional question that merits further study is that mood is regulated by sex-specific mechanisms not yet entirely understood [142]. The fact that women show a greater $\mathrm{AD}$ incidence may be related to this gender trait.

All the above stress-related mechanism impact on ILPs actions in the brain. In general terms we should consider that stress hormones such as glucocorticoids -that are dysregulated in chronic stress conditions [143], may elicit ILP resistance [144-146]. And as discussed above, ILP resistance may account for many of the pathological changes in AD. A less evident aspect of stress effects on ILP activity is that they may interrupt the connection between peripheral ILPs and the brain by hampering their entrance in response to increased brain activity. Indeed, stress exposure reduces activation of hippocampal IGF-I receptors in response to environmental enrichment (Fig. 2), a well-established stimulator of the entrance of ILPs in the brain [69], and widely documented in experimental studies as a protection against AD pathology [147-150].

\section{Mental activity}

Resilience to AD and other neurodegenerative diseases has been related to cognitive reserve [151]. This is a concept coined to explain individual differences in brain aging trajectories and in the responses to brain damage [152]. Cognitive reserve will rely in the amount of neuronal resources that each individual has available, which theoretically may be reflected in brain architecture. Neuronal resources are the sum of inherited intelligence traits and of the extent each individual has used them. The latter is a reflection of the level of education of each individual. Thus, cognitive reserve is in part genetically acquired, and in part, environmental-dependent. Accordingly, the amount of cognitive reserve individually determined would account for the degree of functional compensation underlying individual differences in healthy and pathological brain aging. In this regard it is important to note that during healthy aging, functional compensation is the norm, as the aged brain utilizes resources that differed from young ones [153]. Hence, age-related functional compensation should be more effective in individuals with larger cognitive reserve.

An example that illustrates the concept of cognitive reserve as a protective trait is that individuals with higher education, or greater mental activity in general, show reduced incidence of dementia [154, 155]. This means that the brain can be stimulated to build cognitive reserve, probably throughout life. Thus, even at late stages of life, cognitive activity likely protects against AD [156]. This is because cognitive reserve is probably built through activity-dependent processes. Numerous neuroprotective mechanisms are activated in response to neuronal activity. These include antioxidant [157, 158], inflammatory [159], cytoprotective [160], neurogenic [161, 162], and synaptogenic [163] processes, to name a few. In turn, all these protective traits can be explained by enhanced ILPs activity. Accordingly, it is important to point out that brain activity in general stimulates uptake of circulating IGF-I by the brain on demand, through processes that we have labeled as "neurotrophic coupling" [69]. In turn, local increases in ILPs will favor antioxidant [30, 81], anti-inflammatory [80, 164], cytoprotective [60], neurogenic [165] and synaptogenic actions $[17,166]$. Although it is clear that the protective actions of increased brain activity cannot be solely ascribed to increased entrance of IGF-I into the brain, it is highly likely that it forms part of the pro-cognitive mechanisms underlying cognitive reserve.

\section{Sleep/wake patterns}

Altered sleep/wake pattern is an early disturbance in $\mathrm{AD}$ patients that seems to present a bidirectional relationship. That is, altered sleep is associated to AD, whereas amyloidosis related to AD alters sleep patterns [167]. Although increased sleep fragmentation is linked to normal aging [168], AD patients present more profound alterations in sleep architecture [169]. While the causal connection with the pathology is under intense scrutiny $[170,171]$, it is well recognized that maintaining a minimal amount of sleep is protective against $\mathrm{AD}$ [172]. Furthermore, better sleep consolidation attenuates the effect of ApoE genotype on AD risk [173]. This poses sleep therapy as an important potential target for $\mathrm{AD}$ prevention [174].

Since the brain flux of beta-amyloid (A $\beta)$ is controlled by the sleep/wake cycle [175], a direct link with brain amyloidosis has been suggested [174]. 

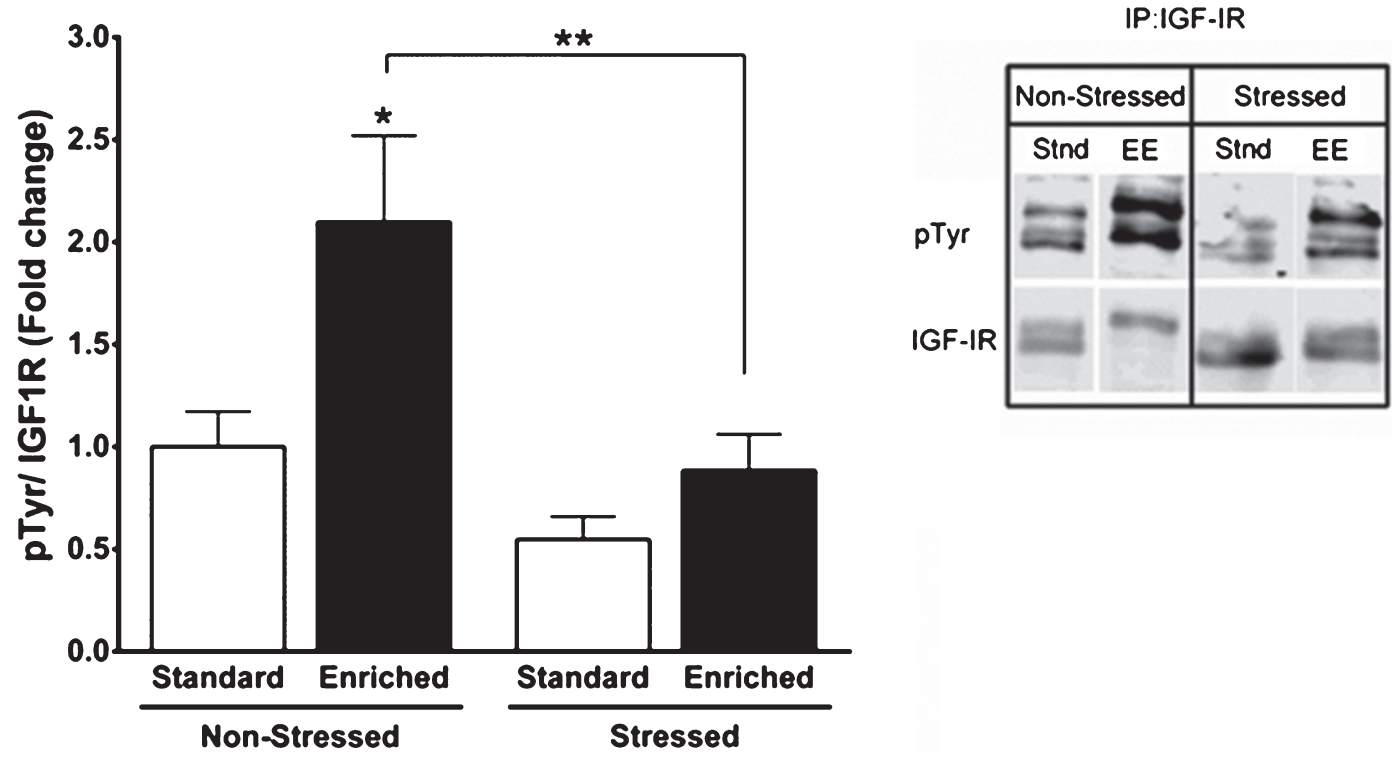

Fig. 2. Stress reduces IGF-I signaling in brain. C57BL/6 mice were exposed to a predator (a rat) or a sham predator (a toy rat) for $10 \mathrm{minutes}$. An environmental enrichment (EE) protocol was used 24 hours later in half of the animals to increase the entrance of IGF-I into the brain [69], while the rest stayed at their home cages (Stand: standard housing). After 2 hours of EE, animals where sacrificed and their hippocampi collected to determine levels of phosphorylated IGF-I receptor. Both the enrichment and the immunoprecipitation + western blot protocols were performed as described [194].

Because an important regulator of sleep patterns are orexin neurons of the lateral hypothalamus [176], and a connection between orexin and $\mathrm{A} \beta$ dynamics was demonstrated [177], orexinergic dysfunction was also proved to be associated to AD [178]. Furthermore, a correlation between CSF levels of orexin and CSF biomarkers of AD such as Tau has been described [179].

The lateral hypothalamus where orexin neurons reside is a classical feeding center where integration of energy availability and arousal takes place [180]. Not surprisingly, orexinergic function is modulated by insulin $[181,182]$, as the sleep/wake cycle is considered to support optimal energy allocation [183]. Thus, insulin signals the fed state to suppress orexinergic activity, leading to reduced physical activity [181]. Conversely, orexin is activated by hunger signals to promote arousal necessary for food-seeking [184].

Indirect evidence also supports an influence of insulin/IGFs on orexin neurons. For example, IGFbinding protein 3 , the major IGF-binding protein, is expressed by orexin neurons, and modulate their function [185]. Also, insulin activity modulates the sleep/wake cycle [186]. In addition, hypothalamic neuronal loss have been found in aged individuals with fragmented sleep [187], which may also be associated to reduced ILPs neuroprotection during aging [188, 189]. Collectively, these data indicate that ILPs affect orexinergic activity and in this way affects the sleep/wake cycle. Whether dysregulated ILP activity originates orexinergic dysfunction leading to disrupted sleep archichecture in AD is a possibility that merits further attention.

\section{Context-dependent actions of insulin peptides in the brain}

Although reductionist approaches have been very useful to analyze complex systems, we have to keep in mind their limitations. Nevertheless, we still tend to disregard contextual nuances when addressing complex biological processes. For instance, insulin resistance is generally considered a pathological disturbance, although it is known that insulin resistance develops in response to different conditions as part of the homeostatic response [159]. Conceivably, physiological resistant states to the action of insulin peptides in the brain may go awry and trigger a cascade of pathological changes. Maladaptive perpetuation of resistant states may be related to life-style, which provides an individual context to disease progression (see Table 1). For example, while glucocorticoid release in response to stress produces insulin resis- 
Table 1

Main lifestyle factors associated to risk of Alzheimer's disease

\begin{tabular}{lcc}
\hline Life-style factor & Relevant mechanisms & References \\
\hline Diet & Diet components such as lipids interfere with brain entrance of insulin/IGF-I. & {$[74,75]$} \\
& Inflammation and oxidative stress produced by unhealthy diets. & {$[78,79]$} \\
Physical Activity & Exercise increases brain sensitivity to insulin and stimulates brain uptake of circulating IGF-I. & {$[68,122]$} \\
Stress & High glucocorticoids elicit insulin/IGF-I resistance. & {$[144-146]$} \\
& Stress reduces brain IGF-I signalling. & Figure 2 \\
Mental Activity & Increased mental activity will increase brain uptake of IGF-I. & {$[69]$} \\
Sleep/Wake Cycle & Insulin modulation of orexin neurons may impact on activity patterns. & {$[181]$} \\
\hline
\end{tabular}

tance as part of the homeostatic repertoire to prepare the body to a life-threatening situation [144], chronic stress in susceptible individuals may cause chronic disruption of insulin signaling in the brain and lead to pathology.

Another key contextual aspect is that the actions of inter-cellular messengers are strictly cell-dependent. It is becoming increasingly clear that each type of brain cell responds to ILPs in specific ways that may even be antagonistic [190], and are strongly driven by cell context [191]. Therefore, it is the sum of celland context-specific responses to ILPs what should be considered. In other words, it would not be the same to modulate ILP activity in astrocytes or neurons for example, or in damaged or intact brain areas. In our effort to understand cellular and molecular pathways driving pathology, these nuances are somewhat overlooked. Administering anti-inflammatory drugs to AD patients based on epidemiological studies of their protective effects may be a typical case of precluding the context.

\section{CONCLUSIONS}

$\mathrm{AD}$ is an age-associated disease of profound incidence in modern societies. It has been argued that AD prevalence has increased in the last century because the age of the population has steadily raised, and now we live enough for the disease to manifest. This may be true, but life-style has also drastically changed in parallel. We may consider that $\mathrm{AD}$ is in part an unwanted cultural by-product and as such, it can theoretically be fought. Until the drug industry develops compounds mimicking or potentiating the protective effects of a healthy life style, it is imperative that public health agencies implement salutary behaviors.

Accordingly, we envisage two main ways to potentiate brain ILPs function through healthy habits. First, by influencing the amount of circulating ILPs input to the brain, as diet, together with physical/mental activity and stress seem to do.
Second, by modulating local ILPs actions. The latter can be brought about by adaptive changes in the sensitivity of brain circuits to ILPs, such as during neuronal plasticity processes involved in mental activity, mood regulation, and sleep/wake cycles.

Compounds modulating ILP actions in the brain in a cell-context dependent fashion may be of therapeutic utility, as they may ameliorate pathological changes associated to AD. Thus, we need to develop new drugs that will counteract ILP imbalances in the proper brain cell type and at the correct time during the course of the disease. For the former, we have to understand better the differences in ILP signaling among brain cell types; for the latter, we need to develop greater insight into the stages that define $\mathrm{AD}$ progress.

\section{CONFLICT OF INTEREST}

The authors state no conflict of interests.

\section{ACKNOWLEDGMENTS}

We thank Ciberned, CAM, and MINECO for their support.

\section{REFERENCES}

[1] A A. About a peculiar disease of the cerebral cortex. By Alois Alzheimer, 1907 (Translated by L. Jarvik and H. Greenson). Alzheimer Dis Assoc Disord. 1987;1(1): 3-8.

[2] Selkoe DJ. Clearing the Brain's Amyloid Cobwebs. Neuron. 2001;32(2):177-80.

[3] Shah H, Albanese E, Duggan C, Rudan I, Langa KM, Carrillo MC, et al. Research priorities to reduce the global burden of dementia by 2025. Lancet Neurol. 2016;15(12):1285-94.

[4] Frere S, Slutsky I. Alzheimer's Disease: From Firing Instability to Homeostasis Network Collapse. Neuron. 2018;97(1):32-58.

[5] De Felice FG, Munoz DP. Opportunities and challenges in developing relevant animal models for Alzheimer's disease. Ageing Research Reviews. 2016;26(Supplement C):112-4. 
[6] Hughes TM, Craft S. The role of insulin in the vascular contributions to age-related dementia. Biochimica et Biophysica Acta (BBA) - Molecular Basis of Disease. 2016;1862(5):983-91.

[7] Mayeux R. Epidemiology of neurodegeneration. Annu Rev Neurosci. 2003;26:81-104.

[8] Reitz C, Brayne C, Mayeux R. Epidemiology of Alzheimer disease. Nat Rev Neurol. 2011;7(3):137-52.

[9] Baumgart M, Snyder HM, Carrillo MC, Fazio S, Kim H, Johns H. Summary of the evidence on modifiable risk factors for cognitive decline and dementia: A population-based perspective. Alzheimers Dement. 2015;11(6):718-26.

[10] Fratiglioni L, Paillard-Borg S, Winblad B. An active and socially integrated lifestyle in late life might protect against dementia. Lancet Neurol. 2004;3(6):343-53.

[11] Pope SK, Shue VM, Beck C. Will a healthy lifestyle help prevent Alzheimer's disease? Annu Rev Public Health. 2003;24:111-32.

[12] Ngandu T, Lehtisalo J, Solomon A, Levalahti E, Ahtiluoto $\mathrm{S}$, Antikainen R, et al. A 2 year multidomain intervention of diet, exercise, cognitive training, and vascular risk monitoring versus control to prevent cognitive decline in at-risk elderly people (FINGER): A randomised controlled trial. Lancet. 2015;385(9984):2255-63.

[13] Kulmala J, Ngandu T, Kivipelto M. Prevention Matters: Time for Global Action and Effective Implementation. J Alzheimers Dis. 2018. 10.3233/JAD-179919

[14] Carro E, Torres-Aleman I. The role of insulin and insulin-like growth factor I in the molecular and cellular mechanisms underlying the pathology of Alzheimer's disease. Eur J Pharmacol. 2004;490(1-3):127-33.

[15] Chiu SL, Chen CM, Cline HT. Insulin Receptor Signaling Regulates Synapse Number, Dendritic Plasticity, and Circuit Function In Vivo. Neuron. 2008;58(5): 708-19.

[16] Gazit N, Vertkin I, Shapira I, Helm M, Slomowitz E, Sheiba M, et al. IGF-1 Receptor Differentially Regulates Spontaneous and Evoked Transmission via Mitochondria at Hippocampal Synapses. Neuron. 2016;89:1-15. doi:10.1016/j.neuron.2015.12.034

[17] Schmeisser MJ, Baumann B, Johannsen S, Vindedal GF, Jensen V, Hvalby OC, et al. IkappaB Kinase/Nuclear Factor kappaB-Dependent Insulin-Like Growth Factor 2 (Igf2) Expression Regulates Synapse Formation and Spine Maturation via Igf 2 Receptor Signaling. J Neurosci. 2012;32(16):5688-703.

[18] O'Neill BT, Lee KY, Klaus K, Softic S, Krumpoch MT, Fentz J, et al. Insulin and IGF-1 receptors regulate FoxOmediated signaling in muscle proteostasis. J Clin Invest. 2016;126(9):3433-46.

[19] Cohen E, Bieschke J, Perciavalle RM, Kelly JW, Dillin A. Opposing Activities Protect Against Age Onset Proteotoxicity. Science. 2006.

[20] Moll L, Ben-Gedalya T, Reuveni H, Cohen E. The inhibition of IGF-1 signaling promotes proteostasis by enhancing protein aggregation and deposition. FASEB J. 2015.

[21] Carro E, Trejo JL, Gomez-Isla T, LeRoith D, TorresAleman I. Serum insulin-like growth factor I regulates brain amyloid-beta levels. Nat Med. 2002;8(12):1390-7.

[22] Chen Y, Zhao Y, Dai CL, Liang Z, Run X, Iqbal K, et al. Intranasal insulin restores insulin signaling, increases synaptic proteins, and reduces Abeta level and microglia activation in the brains of 3xTg-AD mice. Exp Neurol. 2014;261:610-9.

[23] Gasparini L, Gouras GK, Wang R, Gross RS, Beal MF, Greengard P, et al. Stimulation of beta-amyloid precursor protein trafficking by insulin reduces intraneuronal betaamyloid and requires mitogen-activated protein kinase signaling. J Neurosci. 2001;21(8):2561-70.

[24] Jacobsen KT, Adlerz L, Multhaup G, Iverfeldt K. Insulin-like growth factor-1 (IGF-1)-induced processing of amyloid-beta precursor protein (APP) and APP-like protein 2 is mediated by different metalloproteinases. J Biol Chem. 2010;285:10223-31.

[25] Cheng CM, Tseng V, Wang J, Wang D, Matyakhina $\mathrm{L}$, Bondy CA. Tau is hyperphosphorylated in the insulin-like growth factor-I null brain. Endocrinology. 2005;146(12):5086-91.

[26] Hong M, Lee VM. Insulin and insulin-like growth factor-1 regulate tau phosphorylation in cultured human neurons. J Biol Chem. 1997;272(31):19547-53.

[27] Echave P, hado-da-Silva G, Arkell RS, Duchen MR, Jacobson J, Mitter R, et al. Extracellular growth factors and mitogens cooperate to drive mitochondrial biogenesis. J Cell Sci. 2009;122:4516-25.

[28] Yin F, Jiang T, Cadenas E. Metabolic triad in brain aging: Mitochondria, insulin/IGF-1 signalling and JNK signalling. Biochem Soc Trans. 2013;41(1):101-5.

[29] Genis L, Davila D, Fernandez S, Pozo-Rodrigalvarez A, Martinez-Murillo R, Torres-Aleman I. Astrocytes require insulin-like growth factor I to protect neurons against oxidative injury. F1000Res. 2014;3:28.

[30] Duarte AI, Santos MS, Oliveira CR, Rego AC. Insulin neuroprotection against oxidative stress in cortical neurons-involvement of uric acid and glutathione antioxidant defenses. Free Radic Biol Med. 2005;39(7): 876-89.

[31] Fernandez AM, Jimenez S, Mecha M, Davila D, Guaza C, Vitorica J, et al. Regulation of the phosphatase calcineurin by insulin-like growth factor I unveils a key role of astrocytes in Alzheimer's pathology. Mol Psychiatry. 2012;17(7):705-18.

[32] Adzovic L, Lynn AE, D'Angelo HM, Crockett AM, Kaercher RM, Royer SE, et al. Insulin improves memory and reduces chronic neuroinflammation in the hippocampus of young but not aged brains. J Neuroinflammation. 2015; $12: 63$.

[33] Lopez-Lopez C, Dietrich MO, Metzger F, Loetscher H, Torres-Aleman I. Disturbed cross talk between insulinlike growth factor I and AMP-activated protein kinase as a possible cause of vascular dysfunction in the amyloid precursor protein/presenilin 2 mouse model of Alzheimer's disease. J Neurosci. 2007;27(4):824-31.

[34] Baldini S, Restani L, Baroncelli L, Coltelli M, Franco R, Cenni MC, et al. Enriched early life experiences reduce adult anxiety-like behavior in rats: A role for insulin-like growth factor 1. J Neurosci. 2013;33(28):11715-23.

[35] Kullmann S, Frank S, Heni M, Ketterer C, Veit R, Haring $\mathrm{HU}$, et al. Intranasal insulin modulates intrinsic reward and prefrontal circuitry of the human brain in lean women. Neuroendocrinology. 2013;97(2):176-82.

[36] Li C-Q, Luo Y-W, Bi F-F, Cui T-T, Song L, Cao W-Y, et al. Development of Anxiety-Like Behavior via Hippocampal IGF-2 Signaling in the Offspring of Parental Morphine Exposure: Effect of Enriched Environment. Neuropsychopharmacology. 2014;39(12):2777-87. 
[37] Hoyer S, Nitsch R, Oesterreich K. Predominant abnormality in cerebral glucose utilization in late-onset dementia of the Alzheimer type: A cross-sectional comparison against advanced late-onset and incipient early-onset cases. J Neural Transm Park Dis Dement Sect. 1991;3(1): $1-14$.

[38] Steen E, Terry BM, Rivera EJ, Cannon JL, Neely $\mathrm{TR}$, Tavares R, et al. Impaired insulin and insulin-like growth factor expression and signaling mechanisms in Alzheimer's disease-is this type 3 diabetes? J Alzheimers Dis. 2005;7(1):63-80.

[39] De Felice FG, Ferreira ST. Inflammation, defective insulin signaling, and mitochondrial dysfunction as common molecular denominators connecting type 2 diabetes to Alzheimer disease. Diabetes. 2014;63(7):2262-72.

[40] Goldwaser EL, Acharya NK, Sarkar A, Godsey G, Nagele RG. Breakdown of the Cerebrovasculature and Blood-Brain Barrier: A Mechanistic Link Between Diabetes Mellitus and Alzheimer's Disease. J Alzheimers Dis. 2016;54(2):445-56.

[41] Gratuze M, Joly-Amado A, Vieau D, Buee L, Blum D. Mutual relationship between Tau and central insulin signalling: Consequences for AD and Tauopathies ? Neuroendocrinology. 2018. 10.1159/000487641

[42] Clemmons DR. Role of insulin-like growth factor iin maintaining normal glucose homeostasis. Horm Res. 2004;62(Suppl 1):77-82.

[43] Carro E, Trejo JL, Spuch C, Bohl D, Heard JM, TorresAleman I. Blockade of the insulin-like growth factor I receptor in the choroid plexus originates Alzheimer's-like neuropathology in rodents: New cues into the human disease? Neurobiol Aging. 2006;27(11):1618-31.

[44] Hamilton G, Proitsi P, Jehu L, Morgan A, Williams $\mathrm{J}$, O'Donovan $\mathrm{MC}$, et al. Candidate gene association study of insulin signaling genes and Alzheimer's disease: Evidence for SOS2, PCK1, and PPARgamma as susceptibility loci. Am J Med Genet B Neuropsychiatr Genet. 2007;144B(4):508-16.

[45] Garcia J, Ahmadi A, Wonnacott A, Sutcliffe W, Nagga $\mathrm{K}$, Soderkvist $\mathrm{P}$, et al. Association of Insulin-Like Growth Factor-1 Receptor Polymorphism in Dementia. Dement Geriatr Cogn Disord. 2006;22(5-6):439-44.

[46] Vargas T, Martinez-Garcia A, Antequera D, Vilella E, Clarimon J, Mateo I, et al. IGF-I gene variability is associated with an increased risk for AD. Neurobiol Aging. 2011;32(3):556-11.

[47] Bruning JC, Gautam D, Burks DJ, Gillette J, Schubert M, Orban PC, et al. Role of Brain Insulin Receptor in Control of Body Weight and Reproduction. Science. 2000;289(5487):2122-5.

[48] Clegg DJ, Riedy CA, Smith KA, Benoit SC, Woods SC. Differential sensitivity to central leptin and insulin in male and female rats. Diabetes. 2003;52(3):682-7.

[49] Aberg D, Johansson P, Isgaard J, Wallin A, Johansson $\mathrm{JO}$, Andreasson U, et al. Increased Cerebrospinal Fluid Level of Insulin-like Growth Factor-II in Male Patients with Alzheimer's Disease. J Alzheimers Dis. 2015;48: 637-46.

[50] Li R, Singh M. Sex Differences in Cognitive Impairment and Alzheimer's Disease. Frontiers in Neuroendocrinology. 2014;35(3):385-403.

[51] Chaudhry M, Wang X, Bamne MN, Hasnain S, Demirci FY, Lopez OL, et al. Genetic variation in imprinted genes is associated with risk of late-onset Alzheimer's disease. J Alzheimers Dis. 2015;44(3):989-94.
[52] Price JL, Morris JC. Tangles and plaques in nondemented aging and "preclinical" Alzheimer's disease. Ann Neurol. 1999;45(3):358-68.

[53] Kenyon C. The plasticity of aging: Insights from longlived mutants. Cell. 2005;120(4):449-60.

[54] Cohen E, Bieschke J, Perciavalle RM, Kelly JW, Dillin A. Opposing activities protect against age-onset proteotoxicity. Science. 2006;313(5793):1604-10.

[55] Cohen E, Dillin A. The insulin paradox: Aging, proteotoxicity and neurodegeneration. Nat Rev Neurosci. 2008;9(10):759-67.

[56] Steculorum SM, Solas M, Br++ning JC. The paradox of neuronal insulin action and resistance in the development of aging-associated diseases. Alzheimer's \& Dementia. 2014;10(1, Supplement):S3-S11.

[57] Kenyon CJ. The genetics of ageing. Nature. 2010;464(7288):504-12.

[58] Gontier G, George C, Chaker Z, Holzenberger M, Aid S. Blocking IGF Signaling in Adult Neurons Alleviates Alzheimer's Disease Pathology through Amyloid-beta Clearance. J Neurosci. 2015;35(33):11500-13.

[59] Freude S, Hettich MM, Schumann C, Stohr O, Koch L, Kohler C, et al. Neuronal IGF-1 resistance reduces Abeta accumulation and protects against premature death in a model of Alzheimer's disease. FASEB J. 2009;23: 3315-24.

[60] Fernandez AM, Torres-Aleman I. The many faces of insulin-like peptide signalling in the brain. Nat Rev Neurosci. 2012;13(4):225-39.

[61] Seino S, Bell GI. Alternative splicing of human insulin receptor messenger RNA. Biochem Biophys Res Commun. 1989;159(1):312-6.

[62] Moxham CP, Duronio V, Jacobs S. Insulin-like growth factor I receptor beta-subunit heterogeneity. Evidence for hybrid tetramers composed of insulin-like growth factor I and insulin receptor heterodimers. J Biol Chem. 1989;264(22):13238-44.

[63] Frasca F, Pandini G, Scalia P, Sciacca L, Mineo R, Costantino A, et al. Insulin receptor isoform A, a newly recognized, high-affinity insulin-like growth factor II receptor in fetal and cancer cells. Mol Cell Biol. 1999;19(5):3278-88.

[64] Moln+ír G, Farag+i N, Kocsis üK, $R+$ zsa M, Lovas S, Boldog E, et al. GABAergic Neurogliaform Cells Represent Local Sources of Insulin in the Cerebral Cortex. The Journal of Neuroscience. 2014;34(4):1133-7.

[65] Gray SM, Aylor KW, Barrett EJ. Unravelling the regulation of insulin transport across the brain endothelial cell. Diabetologia. 2017

[66] Aguado F, Sanchez-Franco F, Rodrigo J, Cacicedo L, Martinez-Murillo R. Insulin-like growth factor Iimmunoreactive peptide in adult human cerebellar Purkinje cells: Co-localization with low-affinity nerve growth factor receptor. Neuroscience. 1994;59(3):641-50.

[67] Andersson IK, Edwall D, Norstedt G, Rozell B, Skottner A, Hansson HA. Differing expression of insulin-like growth factor I in the developing and in the adult rat cerebellum. Acta Physiol Scand. 1988;132(2):167-73.

[68] Carro E, Nunez A, Busiguina S, Torres-Aleman I. Circulating insulin-like growth factor I mediates effects of exercise on the brain. J Neurosci. 2000;20(8):2926-33.

[69] Nishijima T, Piriz J, Duflot S, Fernandez AM, Gaitan G, Gomez-Pinedo U, et al. Neuronal activity drives localized blood-brain-barrier transport of serum insulin-like growth factor-I into the CNS. Neuron. 2010;67(5):834-46. 
[70] Ayer-le Lievre C, Stahlbom PA, Sara VR. Expression of IGF-I and -II mRNA in the brain and craniofacial region of the rat fetus. Development. 1991;111(1):105-15.

[71] Klimova B, Kuca K. Multi-Nutrient Dietary Intervention Approach to the Management of Alzheimer's Disease - A Mini-Review. Curr Alzheimer Res. 2016;13(12):1312-8.

[72] Fu Z, Wu J, Nesil T, Li MD, Aylor KW, Liu Z. Longterm high-fat diet induces hippocampal microvascular insulin resistance and cognitive dysfunction. Am J Physiol Endocrinol Metab. 2017;312(2):E89-E97.

[73] Bird SR, Hawley JA. Update on the effects of physical activity on insulin sensitivity in humans. BMJ Open Sport Exerc Med. 2016;2(1):e000143.

[74] Dietrich MO, Muller A, Bolos M, Carro E, Perry ML, Portela LV, et al. Western Style Diet Impairs Entrance of Blood-Borne Insulin-like Growth Factor-1 into the Brain. Neuromolecular Med. 2007;9(4):324-30.

[75] Begg DP. Insulin transport into the brain and cerebrospinal fluid. Vitam Horm. 2015;98:229-48.

[76] Sajan M, Hansen B, Ivey R 3rd, Sajan J, Ari C, Song $\mathrm{S}$, et al. Brain Insulin Signaling Is Increased in Insulin-Resistant States and Decreases in FOXOs and PGC-1alpha and Increases in Abeta1-40/42 and Phospho-Tau May Abet Alzheimer Development. Diabetes. 2016;65(7):1892-903.

[77] Anthony K, Reed LJ, Dunn JT, Bingham E, Hopkins D, Marsden PK, et al. Attenuation of insulin-evoked responses in brain networks controlling appetite and reward in insulin resistance: The cerebral basis for impaired control of food intake in metabolic syndrome? Diabetes. 2006;55(11):2986-92.

[78] Businaro R, Corsi M, Asprino R, Di Lorenzo C, Laskin D, Corbo RM, et al. Modulation Of Inflammation As A Way Of Delaying Alzheimer's Disease Progression: The Diet's Role. Curr Alzheimer Res. 2017;15:363-80.

[79] Freeman LR, Haley-Zitlin V, Rosenberger DS, Granholm AC. Damaging effects of a high-fat diet to the brain and cognition: A review of proposed mechanisms. Nutr Neurosci. 2014;17(6):241-51.

[80] Fernandez AM, Jimenez S, Mecha M, Davila D, Guaza C, Vitorica J, et al. Regulation of the phosphatase calcineurin by insulin-like growth factor I unveils a key role of astrocytes in Alzheimer's pathology. Mol Psychiatry. 2012;17(7):705-18.

[81] Crowe E, Sell C, Thomas JD, Johannes GJ, Torres C. Activation of proteasome by insulin-like growth factor-I may enhance clearance of oxidized proteins in the brain. Mech Ageing Dev. 2009;130:793-800.

[82] Sun Q, Li J, Gao F. New insights into insulin: The anti-inflammatory effect and its clinical relevance. World Journal of Diabetes. 2014;5(2):89-96.

[83] Johnson AM, Olefsky JM. The origins and drivers of insulin resistance. Cell. 2013;152(4):673-84.

[84] Spielman LJ, Little JP, Klegeris A. Inflammation and insulin/IGF-1 resistance as the possible link between obesity and neurodegeneration. J Neuroimmunol. 2014;273(1-2):8-21.

[85] Remington R, Bechtel C, Larsen D, Samar A, Page R, Morrell $\mathrm{C}$, et al. Maintenance of Cognitive Performance and Mood for Individuals with Alzheimer's Disease Following Consumption of a Nutraceutical Formulation: A One-Year, Open-Label Study. J Alzheimers Dis. 2016;51(4):991-5.

[86] Taylor MK, Sullivan DK, Swerdlow RH, Vidoni ED, Morris JK, Mahnken JD, et al. A high-glycemic diet is associated with cerebral amyloid burden in cognitively normal older adults. Am J Clin Nutr. 2017;106:1463-1470.

[87] Anastasiou CA, Yannakoulia M, Kosmidis MH, Dardiotis E, Hadjigeorgiou GM, Sakka P, et al. Mediterranean diet and cognitive health: Initial results from the Hellenic Longitudinal Investigation of Ageing and Diet. PLoS One. 2017;12(8):e0182048.

[88] Morris MC, Tangney CC, Wang Y, Sacks FM, Bennett DA, Aggarwal NT. MIND diet associated with reduced incidence of Alzheimer's disease. Alzheimers Dement. 2015;11(9):1007-14.

[89] Gardener S, Gu Y, Rainey-Smith SR, Keogh JB, Clifton PM, Mathieson SL, et al. Adherence to a Mediterranean diet and Alzheimer's disease risk in an Australian population. Transl Psychiatry. 2012;2:e164.

[90] Seneff S, Wainwright G, Mascitelli L. Nutrition and Alzheimer's disease: The detrimental role of a high carbohydrate diet. Eur J Intern Med. 2011;22(2): 134-40.

[91] Barnard ND, Bunner AE, Agarwal U. Saturated and trans fats and dementia: A systematic review. Neurobiol Aging. 2014;35(Suppl 2):S65-73.

[92] Ylilauri MP, Voutilainen S, Lonnroos E, Mursu J, Virtanen HE, Koskinen TT, et al. Association of dietary cholesterol and egg intakes with the risk of incident dementia or Alzheimer disease: The Kuopio Ischaemic Heart Disease Risk Factor Study. Am J Clin Nutr. 2017;105(2):476-84.

[93] Petersson SD, Philippou E. Mediterranean Diet, Cognitive Function, and Dementia: A Systematic Review of the Evidence. Adv Nutr. 2016;7(5):889-904.

[94] Dye L, Boyle NB, Champ C, Lawton C. The relationship between obesity and cognitive health and decline. Proc Nutr Soc. 2017;76(4):443-54.

[95] Singh-Manoux A, Dugravot A, Shipley M, Brunner EJ, Elbaz A, Sabia S, et al. Obesity trajectories and risk of dementia: 28 years of follow-up in the Whitehall II Study. Alzheimers Dement. 2018;14(2):178-86.

[96] Kivimaki M, Luukkonen R, Batty GD, Ferrie JE, Pentti J, Nyberg ST, et al. Body mass index and risk of dementia: Analysis of individual-level data from 1.3 million individuals. Alzheimers Dement. 2018;14(5):601-9.

[97] Pase MP, Himali JJ, Beiser AS, Aparicio HJ, Satizabal CL, Vasan RS, et al. Sugar- and Artificially Sweetened Beverages and the Risks of Incident Stroke and Dementia: A Prospective Cohort Study. Stroke. 2017;48(5):1139-46.

[98] Engelhart MJ, Geerlings MI, Ruitenberg A, Van Swieten JC, Hofman A, Witteman JC, et al. Diet and risk of dementia: Does fat matter?: The Rotterdam Study. Neurology. 2002;59(12):1915-21.

[99] Samieri C, Morris MC, Bennett DA, Berr C, Amouyel P, Dartigues JF, et al. Fish intake, genetic predisposition to alzheimer's disease and decline in global cognition and memory in five cohorts of older persons. Am J Epidemiol. 2017.

[100] Zhang Y, Chen J, Qiu J, Li Y, Wang J, Jiao J. Intakes of fish and polyunsaturated fatty acids and mild-to-severe cognitive impairment risks: A dose-response meta-analysis of 21 cohort studies. Am J Clin Nutr. 2016;103(2):330-40.

[101] Qin B, Xun P, Jacobs DR Jr, Zhu N, Daviglus ML, Reis JP, et al. Intake of niacin, folate, vitamin B-6, and vitamin B-12 through young adulthood and cognitive function in midlife: The Coronary Artery Risk Development in Young Adults (CARDIA) study. Am J Clin Nutr. 2017;106(4):1032-40. 
[102] Smith AD, Refsum H. Homocysteine, B Vitamins, and Cognitive Impairment. Annu Rev Nutr. 2016;36:211-39.

[103] Farina N, Llewellyn D, Isaac M, Tabet N. Vitamin E for Alzheimer's dementia and mild cognitive impairment. Cochrane Database Syst Rev. 2017;4:CD002854.

[104] Knochel C, Voss M, Gruter F, Alves GS, Matura S, Sepanski B, et al. Omega-3 Fatty Acids: Repurposing Opportunities for Cognition and Biobehavioral Disturbances in MCI and Dementia. Curr Alzheimer Res. 2017;14(3):240-54.

[105] Chen H, Liu S, Ji L, Wu T, Ji Y, Zhou Y, et al. Folic Acid Supplementation Mitigates Alzheimer's Disease by Reducing Inflammation: A Randomized Controlled Trial. Mediators Inflamm. 2016;2016:5912146.

[106] de Wilde MC, Vellas B, Girault E, Yavuz AC, Sijben JW. Lower brain and blood nutrient status in Alzheimer's disease: Results from meta-analyses. Alzheimers Dement (N Y). 2017;3(3):416-31.

[107] Gillette-Guyonnet S, Nourhashemi F, Andrieu S, de Glisezinski I, Ousset PJ, Riviere D, et al. Weight loss in Alzheimer disease. Am J Clin Nutr. 2000;71(2):637S-42S.

[108] Tamura BK, Masaki KH, Blanchette P. Weight loss in patients with Alzheimer's disease. J Nutr Elder. 2007;26(3-4):21-38

[109] Cova I, Clerici F, Rossi A, Cucumo V, Ghiretti R, Maggiore L, et al. Weight Loss Predicts Progression of Mild Cognitive Impairment to Alzheimer's Disease. PLoS One. 2016;11(3):e0151710.

[110] Venturelli M, Cè E, Limonta E, Muti E, Scarsini R, Brasioli A, et al. Possible Predictors of Involuntary Weight Loss in Patients with Alzheimer's Disease. PLoS One. 2016;11(6): 0157384.

[111] Saltiel AR, Kahn CR. Insulin signalling and the regulation of glucose and lipid metabolism. Nature. 2001;414(6865):799-806.

[112] Ginis KA, Heisz J, Spence JC, Clark IB, Antflick J, Ardern CI, et al. Formulation of evidence-based messages to promote the use of physical activity to prevent and manage Alzheimer's disease. BMC Public Health. 2017;17(1):209.

[113] Narkar VA, Downes M, Yu RT, Embler E, Wang YX, Banayo E, et al. AMPK and PPARdelta agonists are exercise mimetics. Cell. 2008;134(3):405-15.

[114] Brown BM, Peiffer JJ, Martins RN. Multiple effects of physical activity on molecular and cognitive signs of brain aging: Can exercise slow neurodegeneration and delay Alzheimer's disease? Mol Psychiatry. 2013;18(8):864-74.

[115] Dougherty RJ, Schultz SA, Boots EA, Ellingson LD, Meyer JD, Van Riper S, et al. Relationships between cardiorespiratory fitness, hippocampal volume, and episodic memory in a population at risk for Alzheimer's disease. Brain Behav. 2017;7(3):e00625.

[116] Pentikainen H, Ngandu T, Liu Y, Savonen K, Komulainen $\mathrm{P}$, Hallikainen $\mathrm{M}$, et al. Cardiorespiratory fitness and brain volumes in men and women in the FINGER study. Age Ageing. 2017;46(2):310-3.

[117] Moore KM, Girens RE, Larson SK, Jones MR, Restivo JL, Holtzman DM, et al. A spectrum of exercise training reduces soluble Abeta in a dose-dependent manner in a mouse model of Alzheimer's disease. Neurobiol Dis. 2016;85:218-24

[118] Barnard ND, Bush AI, Ceccarelli A, Cooper J, de Jager CA, Erickson KI, et al. Dietary and lifestyle guidelines for the prevention of Alzheimer's disease. Neurobiology of Aging. 2014;35(Supplement 2(0)):S74-S8.
[119] Morris JK, Vidoni ED, Johnson DK, Van Sciver A, Mahnken JD, Honea RA, et al. Aerobic exercise for Alzheimer's disease: A randomized controlled pilot trial. PLoS One. 2017;12(2):e0170547.

[120] Kim MJ, Han CW, Min KY, Cho CY, Lee CW, Ogawa Y, et al. Physical Exercise with Multicomponent Cognitive Intervention for Older Adults with Alzheimer's Disease: A 6-Month Randomized Controlled Trial. Dement Geriatr Cogn Dis Extra. 2016;6(2):222-32.

[121] Forbes D, Thiessen EJ, Blake CM, Forbes SC, Forbes S. Exercise programs for people with dementia. Cochrane Database Syst Rev. 2013;12:CD006489.

[122] Muller AP, Gnoatto J, Moreira JD, Zimmer ER, Haas CB, Lulhier $\mathrm{F}$, et al. Exercise increases insulin signaling in the hippocampus: Physiological effects and pharmacological impact of intracerebroventricular insulin administration in mice. Hippocampus. 2011;21(10):1082-92.

[123] Ari Z, Kutlu N, Sami UB, Taneli F, Buyukyazi G, Tavli T. Serum testosterone, growth hormone, and insulin-like growth factor-1 levels, mental reaction time, and maximal aerobic exercise in sedentary and long-term physically trained elderly males. Int J Neurosci. 2004;114(5):623-37.

[124] Berg U, Bang P. Exercise and circulating insulin-like growth factor I. Horm Res. 2004;62(Suppl 1):50-8.

[125] Bonnefoy M, Kostka T, Patricot MC, Berthouze SE, Mathian B, Lacour JR. Influence of acute and chronic exercise on insulin-like growth factor-I in healthy active elderly men and women. Aging (Milano). 1999;11(6):373-9.

[126] Carro E, Trejo JL, Busiguina S, Torres-Aleman I. Circulating insulin-like growth factor I mediates the protective effects of physical exercise against brain insults of different etiology and anatomy. J Neurosci. 2001;21(15):5678-84.

[127] Trejo JL, Carro E, Torres-Aleman I. Circulating insulinlike growth factor I mediates exercise-induced increases in the number of new neurons in the adult hippocampus. J Neurosci. 2001;21(5):1628-34.

[128] Mattson MP. Neuroprotective signaling and the aging brain: Take away my food and let me run(1). Brain Res. 2000;886(1-2):47-53.

[129] Trejo JL, Carro E, Nunez A, Torres-Aleman I. Sedentary life impairs self-reparative processes in the brain: The role of serum insulin-like growth factor-I. Rev Neurosci. 2002;13(4):365-74.

[130] Freese J, Klement RJ, Ruiz-Nunez B, Schwarz S, Lotzerich H. The sedentary (r)evolution: Have we lost our metabolic flexibility? F1000Res. 2017;6:1787.

[131] Spalletta G, Musicco M, Padovani A, Rozzini L, Perri R, Fadda L, et al. Neuropsychiatric symptoms and syndromes in a large cohort of newly diagnosed, untreated patients with Alzheimer disease. Am J Geriatr Psychiatry. 2010;18(11):1026-35.

[132] M FM, Molano A, Castro J, Zarranz JJ. Prevalence of neuropsychiatric symptoms in mild cognitive impairment and Alzheimer's disease, and its relationship with cognitive impairment. Curr Alzheimer Res. 2010;7(6):517-26.

[133] Wang J, Yu JT, Wang HF, Meng XF, Wang C, Tan CC, et al. Pharmacological treatment of neuropsychiatric symptoms in Alzheimer's disease: A systematic review and metaanalysis. J Neurol Neurosurg Psychiatry. 2015;86(1): 101-9.

[134] Trinh NH, Hoblyn J, Mohanty S, Yaffe K. Efficacy of cholinesterase inhibitors in the treatment of neuropsychiatric symptoms and functional impairment in Alzheimer disease: A meta-analysis. JAMA. 2003;289(2):210-6. 
[135] Mourao RJ, Mansur G, Malloy-Diniz LF, Castro CE, Diniz BS. Depressive symptoms increase the risk of progression to dementia in subjects with mild cognitive impairment: Systematic review and meta-analysis. Int J Geriatr Psychiatry. 2015 ; 31:905-911.

[136] Van der MS, Fransen E, Struyfs H, Luyckx J, Marien P, Saerens J, et al. Depression in Mild Cognitive Impairment is associated with Progression to Alzheimer's Disease: A Longitudinal Study. J Alzheimers Dis. 2014; 42:12391250.

[137] Gold PW. The organization of the stress system and its dysregulation in depressive illness. Mol Psychiatry. 2015;20(1):32-47.

[138] Sotiropoulos I, Sousa N. Tau as the Converging Protein between Chronic Stress and Alzheimer's Disease Synaptic Pathology. Neurodegener Dis. 2016;16(1-2):22-5.

[139] Ricci S, Fuso A, Ippoliti F, Businaro R. Stress-induced cytokines and neuronal dysfunction in Alzheimer's disease. J Alzheimers Dis. 2012;28(1):11-24.

[140] Tortosa-Martinez J, Clow A. Does physical activity reduce risk for Alzheimer's disease through interaction with the stress neuroendocrine system? Stress. 2012;15(3):243-61.

[141] Seo JS, Lee KW, Kim TK, Baek IS, Im JY, Han PL. Behavioral stress causes mitochondrial dysfunction via $\mathrm{ABAD}$ up-regulation and aggravates plaque pathology in the brain of a mouse model of Alzheimer disease. Free Radic Biol Med. 2011;50(11):1526-35.

[142] Bale TL, Epperson CN. Sex differences and stress across the lifespan. Nat Neurosci. 2015;18(10):1413-20.

[143] Nicolaides NC, Kyratzi E, Lamprokostopoulou A, Chrousos GP, Charmandari E. Stress, the stress system and the role of glucocorticoids. Neuroimmunomodulation. 2015;22(1-2):6-19.

[144] Rizza RA, Mandarino LJ, Gerich JE. Cortisol-induced insulin resistance in man: Impaired suppression of glucose production and stimulation of glucose utilization due to a postreceptor detect of insulin action. J Clin Endocrinol Metab. 1982;54(1):131-8

[145] Prummel MF, Wiersinga WM, Oosting H, Endert E. The effect of long-term prednisone treatment on growth hormone and insulin-like growth factor-1. J Endocrinol Invest. 1996;19(9):620-3.

[146] Steiner JL, Bardgett ME, Wolfgang L, Lang CH, Stocker SD. Glucocorticoids attenuate the central sympathoexcitatory actions of insulin. J Neurophysiol. 2014;112(10):2597-604.

[147] Lazarov O, Robinson J, Tang YP, Hairston IS, KoradeMirnics Z, Lee VM, et al. Environmental enrichment reduces abeta levels and amyloid deposition in transgenic mice. Cell. 2005;120(5):701-13.

[148] Wolf SA, Kronenberg G, Lehmann K, Blankenship A, Overall R, Staufenbiel M, et al. Cognitive and physical activity differently modulate disease progression in the amyloid precursor protein (APP)-23 model of Alzheimer's disease. Biol Psychiatry. 2006;60(12):1314-23.

[149] Jankowsky JL, Melnikova T, Fadale DJ, Xu GM, Slunt $\mathrm{HH}$, Gonzales V, et al. Environmental enrichment mitigates cognitive deficits in a mouse model of Alzheimer's disease. J Neurosci. 2005;25(21):5217-24.

[150] Herring A, Blome M, Ambree O, Sachser N, Paulus W, Keyvani K. Reduction of Cerebral Oxidative Stress Following Environmental Enrichment in Mice with Alzheimer-Like Pathology. Brain Pathol. 2009; 20: 166-175.
[151] Adam S, Bonsang E, Grotz C, Perelman S. Occupational activity and cognitive reserve: Implications in terms of prevention of cognitive aging and Alzheimer's disease. Clin Interv Aging. 2013;8:377-90.

[152] Stern Y. Cognitive reserve. Neuropsychologia. 2009;47(10):2015-28.

[153] Park DC, Reuter-Lorenz P. The adaptive brain: Aging and neurocognitive scaffolding. Annu Rev Psychol. 2009;60:173-96.

[154] Rundek T, Bennett DA. Cognitive leisure activities, but not watching TV, for future brain benefits. Neurology. 2006;66(6):794-5.

[155] Stern Y, Gurland B, Tatemichi TK, Tang MX, Wilder D, Mayeux R. Influence of education and occupation on the incidence of Alzheimer's disease. JAMA. 1994;271(13):1004-10.

[156] Sajeev G, Weuve J, Jackson JW, VanderWeele TJ, Bennett DA, Grodstein F, et al. Late-life Cognitive Activity and Dementia: A Systematic Review and Bias Analysis. Epidemiology. 2016;27(5):732-42.

[157] Habas A, Hahn J, Wang X, Margeta M. Neuronal activity regulates astrocytic Nrf2 signaling. Proc Natl Acad Sci U S A. 2013;110(45):18291-6.

[158] Papadia S, Soriano FX, Leveille F, Martel MA, Dakin KA, Hansen HH, et al. Synaptic NMDA receptor activity boosts intrinsic antioxidant defenses. Nat Neurosci. 2008;11(4):476-87.

[159] Xanthos DN, Sandkuhler J. Neurogenic neuroinflammation: Inflammatory CNS reactions in response to neuronal activity. Nat Rev Neurosci. 2014;15(1):43-53.

[160] Mennerick S, Zorumski CF. Neural activity and survival in the developing nervous system. Mol Neurobiol. 2000;22(1-3):41-54.

[161] Tashiro A, Sandler VM, Toni N, Zhao C, Gage FH. NMDA-receptor-mediated, cell-specific integration of new neurons in adult dentate gyrus. Nature. 2006;442(7105): 929-33.

[162] Kempermann G, Brandon EP, Gage FH. Environmental stimulation of $129 / \mathrm{SvJ}$ mice causes increased cell proliferation and neurogenesis in the adult dentate gyrus. Curr Biol. 1998;8(16):939-42.

[163] Black JE, Isaacs KR, Anderson BJ, Alcantara AA, Greenough WT. Learning causes synaptogenesis, whereas motor activity causes angiogenesis, in cerebellar cortex of adult rats. Proc Natl Acad Sci U S A. 1990;87(14): 5568-72.

[164] Adzovic L, Lynn AE, D'Angelo HM, Crockett AM, Kaercher RM, Royer SE, et al. Insulin improves memory and reduces chronic neuroinflammation in the hippocampus of young but not aged brains. J Neuroinflammation. 2015;12(1):63.

[165] Ziegler AN, Levison SW, Wood TL. Insulin and IGF receptor signalling in neural-stem-cell homeostasis. Nat Rev Endocrinol. 2015;11(3):161-70.

[166] xon-Salazar TJ, Fourgeaud L, Tyler CM, Poole JR, Park JJ, Boulanger LM. MHC Class I Limits Hippocampal Synapse Density by Inhibiting Neuronal Insulin Receptor Signaling. The Journal of Neuroscience. 2014;34(35):11844-56.

[167] Ju YE, Lucey BP, Holtzman DM. Sleep and Alzheimer disease pathology-a bidirectional relationship. Nat Rev Neurol. 2014;10(2):115-9.

[168] Zdanys KF, Steffens DC. Sleep Disturbances in the Elderly. Psychiatr Clin North Am. 2015;38(4):723-41. 
[169] Peter-Derex L, Yammine P, Bastuji H, Croisile B. Sleep and Alzheimer's disease. Sleep Med Rev. 2015;19:29-38.

[170] Tabuchi M, Lone SR, Liu S, Liu Q, Zhang J, Spira AP, et al. Sleep interacts with abeta to modulate intrinsic neuronal excitability. Curr Biol. 2015;25(6):702-12.

[171] Mander BA, Winer JR, Jagust WJ, Walker MP. Sleep: A Novel Mechanistic Pathway, Biomarker, and Treatment Target in the Pathology of Alzheimer's Disease? Trends Neurosci. 2016;39(8):552-66.

[172] Spira AP, Chen-Edinboro LP, Wu MN, Yaffe K. Impact of sleep on the risk of cognitive decline and dementia. Curr Opin Psychiatry. 2014;27(6):478-83.

[173] Lim AS, Yu L, Kowgier M, Schneider JA, Buchman AS, Bennett DA. Modification of the relationship of the apolipoprotein E epsilon4 allele to the risk of Alzheimer disease and neurofibrillary tangle density by sleep. JAMA Neurol. 2013;70(12):1544-51.

[174] Boespflug EL, Iliff JJ. The Emerging Relationship Between Interstitial Fluid-Cerebrospinal Fluid Exchange, Amyloid-beta, and Sleep. Biol Psychiatry. 2018;83(4):328-36.

[175] Kang JE, Lim MM, Bateman RJ, Lee JJ, Smyth LP, Cirrito JR, et al. Amyloid-beta dynamics are regulated by orexin and the sleep-wake cycle. Science. 2009;326(5955): 1005-7.

[176] Sakurai T. The neural circuit of orexin (hypocretin): Maintaining sleep and wakefulness. Nat Rev Neurosci. 2007;8(3):171-81.

[177] Kang JE, Lim MM, Bateman RJ, Lee JJ, Smyth LP, Cirrito JR, et al. Amyloid-beta dynamics are regulated by orexin and the sleep-wake cycle. Science. 2009;326(5955): 1005-7.

[178] Roh JH, Jiang H, Finn MB, Stewart FR, Mahan TE, Cirrito JR, et al. Potential role of orexin and sleep modulation in the pathogenesis of Alzheimer's disease. J Exp Med. 2014;211(13):2487-96.

[179] Liguori C, Romigi A, Nuccetelli M, Zannino S, Sancesario G, Martorana A, et al. Orexinergic System Dysregulation, Sleep Impairment, and Cognitive Decline in Alzheimer Disease. JAMA Neurol. 2014.

[180] Gutierrez R, Lobo MK, Zhang F, de Lecea L. Neural integration of reward, arousal, and feeding: Recruitment of VTA, lateral hypothalamus, and ventral striatal neurons. IUBMB Life. 2011;63(10):824-30.

[181] Silva JP, von MF, Howell J, Thorens B, Wolfrum C, Stoffel M. Regulation of adaptive behaviour during fasting by hypothalamic Foxa2. Nature. 2009;462(7273): 646-50.

[182] Moriguchi T, Sakurai T, Nambu T, Yanagisawa M, Goto $\mathrm{K}$. Neurons containing orexin in the lateral hypothalamic area of the adult rat brain are activated by insulin-induced acute hypoglycemia. Neurosci Lett. 1999;264(1-3):101-4.
[183] Skora S, Mende F, Zimmer M. Energy Scarcity Promotes a Brain-wide Sleep State Modulated by Insulin Signaling in C. elegans. Cell Rep. 2018;22(4):953-66.

[184] Yamanaka A, Beuckmann CT, Willie JT, Hara J, Tsujino $\mathrm{N}$, Mieda $\mathrm{M}$, et al. Hypothalamic orexin neurons regulate arousal according to energy balance in mice. Neuron. 2003;38(5):701-13.

[185] Honda M, Eriksson KS, Zhang S, Tanaka S, Lin L, Salehi A, et al. IGFBP3 colocalizes with and regulates hypocretin (orexin). PLoS One. 2009;4(1):e4254.

[186] Metaxakis A, Tain LS, Gronke S, Hendrich O, Hinze Y, Birras U, et al. Lowered insulin signalling ameliorates age-related sleep fragmentation in Drosophila. PLoS Biol. 2014;12(4):e1001824.

[187] Lim AS, Ellison BA, Wang JL, Yu L, Schneider JA, Buchman AS, et al. Sleep is related to neuron numbers in the ventrolateral preoptic/intermediate nucleus in older adults with and without Alzheimer's disease. Brain. 2014;137(Pt 10):2847-61.

[188] Trejo JL, Carro E, Lopez-Lopez C, Torres-Aleman I. Role of serum insulin-like growth factor I in mammalian brain aging. Growth Horm IGF Res. 2004;14(Suppl A):39-43.

[189] Frolich L, Blum-Degen D, Bernstein HG, Engelsberger S, Humrich J, Laufer S, et al. Brain insulin and insulin receptors in aging and sporadic Alzheimer's disease. J Neural Transm. 1998;105(4-5):423-38.

[190] Pierce SB, Costa M, Wisotzkey R, Devadhar S, Homburger SA, Buchman AR, et al. Regulation of DAF-2 receptor signaling by human insulin and ins-1, a member of the unusually large and diverse $\mathrm{C}$. elegans insulin gene family. Genes Dev. 2001;15(6):672-86.

[191] Franco C, Fernandez S, Torres A, I. Frataxin deficiency unveils cell-context dependent actions of insulinlike growth factor I on neurons. Mol Neurodegener. 2012;7(1):51.

[192] Boldrini M, Fulmore CA, Tartt AN, Simeon LR, Pavlova I, Poposka V, et al. Human Hippocampal Neurogenesis Persists throughout Aging. Cell Stem Cell. 2018;22(4):589-99 e5.

[193] Sorrells SF, Paredes MF, Cebrian-Silla A, Sandoval K, Qi D, Kelley KW, et al. Human hippocampal neurogenesis drops sharply in children to undetectable levels in adults. Nature. 2018;555(7696):377-81.

[194] Trueba-Saiz A, Fernandez AM, Nishijima T, Mecha M, Santi A, Munive V, et al. Circulating Insulin-Like Growth Factor I Regulates Its Receptor in the Brain of Male Mice. Endocrinology. 2017;158(2):349-55. 